\title{
Mechanism of information model development for company brand assessment within marketing strategy
}

\author{
Galina Astratova \\ Department of Economics of Housing, Communal Services \\ and Energy \\ Ural State University of Economics \\ Ekaterinburg, Russia \\ Evgenii Sinicin \\ Department of Financial Management \\ Ural Federal University \\ Ekaterinburg, Russia
}

\author{
Elena Toporkova \\ Department of Economics of Housing, Communal Services \\ and Energy \\ Ural State University of economics \\ Ekaterinburg, Russia \\ t.e.v.16@yandex.ru \\ Ludmila Frishberg \\ Department of Economics of Housing, Communal Services \\ and Energy \\ Ural State University of Economics \\ Ekaterinburg, Russia
}

\section{Irina Karabanova \\ Department of Economics of Housing, Communal Services and Energy \\ Ural State University of Economics \\ Ekaterinburg, Russia}

\begin{abstract}
Intellectual property is one of the main components of a marketing strategy in the assessment of a brand value.
\end{abstract}

Keywords - brand, trademark, intellectual property, intellectual property valuation, marketing, marketing strategy

\section{INTRODUCTION}

The analysis of literature available $[1-4,10-12,15,17-19$, etc.] demonstrates that currently in Russia there are a lot of discussions concerning the categorical framework and application of a brand and intellectual property. This stems from the fact that various regulations and guidelines are differently interpreted by marketing experts and lawyers.

Thus, marketing experts identify a brand as the system uniting goods and their characteristics, a trademark and the way it is perceived by consumers, as well as the concept of a manufacturer (seller) with regard to goods, the trademark ${ }^{1}$ (further to be referred to as the TM) and consumers. The brand makes it possible for the consumer to identify goods among competitors and to confine a complex, multistage process of decision making regarding a purchase to two stages: problem awareness and purchase as such.
Lawyers perceive intellectual property (further to be referred to as the IP) as the legal right of some persons for IP assets of the same or other persons [14, pp. 7]. The term IP has many definitions: capital contribution, an image of a product or service, a commercialized object contributing to company competitiveness. At the same time, as rightly been said by N.V. Bulgakova, "In fact, there is a variety of enterprises which patents for inventions simply gather dust, it is impossible to find their practical use, and even more difficult to sell. However, their protection and registration cost money. Even if registered, the trademarks are almost identical to each other. As a result, LLC Romashkovoye Pole appears alongside with LLC Pole Romashkovoye. Does it really provide a real competitive advantage? As I see it, only large enterprises are capable to derive profit from their $\mathrm{IA}^{2}$, and everything, which is either developed at small enterprises or lost in their archieve basements or bought at a cheap rate, results in more spending for development than the final profit [1]

\footnotetext{
${ }^{1}$ Trademark is a recognizable name (term, sign, design or expression) or a design solution which identifies products or services of a particular seller or a group of sellers in order to distinguish the products from competitors.
} 
It is worth mentioning that the Russian legislation does not consider the term 'brand' as a concept and hence cannot be legally protected. Legal protection in the Russian Federation is only applicable to trademarks. In particular, this is reflected in the following regulations:

- Right to trademarks, which is a type of objects of IP rights, belongs to the rights to means of individualization of legal entities, products, works, services and enterprises.

- Exclusive right to a trademark confirmed by the certificate of trademark.

- Right to a trademark ownership for TM use; TM order; prohibition of TM use by other persons.

- Civil, administrative and criminal liability for illegal use of a trademark ${ }^{3}$.

This legal framework enables registering companies having the same name if they belong to different industrial sectors or located in different regions. Unscrupulos enterpreneurs can register intellectual property thus bypassing owners of brands and real product planners. As a result, many authors are either forced to redeem personal inventions or refuse to use them. Moreover, brand registration involves tangible financial expenses, which is not always beneficial to authors and does not always pay off within the expected period of a brand use.

The previously mentioned information makes it possible to draw the general layout of brand design as a registered trademark. The following are the main stages of trademark design and registration:

1. To set the goal of market positioning.

2. To determine basic elements of a trademark as symbols of an industry or a company.

3. To chose a trademark sketch from among two or three options in order to form a focus group.

4. To set the task of chosing a particular mark following the results of the focus group discussion from among trademarks registered in Russia and to search in the Database of the Russian Agency for Patents and Trademarks (Rospatent) in order to identify similar marks.

5. To compare the selected sketches with information selected at the search stage. If necessary, to adjust the mark to avoid similarity with already registered marks.

6. To approve the selected mark.

7. To issue an order for a trademark.

8. To submit a mark for registration as a trademark.

9. To manage records concerning the order for a trademark.

10. To obtain a copyright protection document (certificate) for a trademark.

\footnotetext{
${ }^{3}$ Trademark is oficially registered one or several elements of a trademark

(TM) being legally effective and legally protective.
}

11. To ensure legal support for the certificate of the trademark.

12. To register a trademark as an intangible asset (further to be referred to as the IA) of an enterprise.

It is extremely difficult to implement the last stage of the abovestated scheme. The reason for this is that the estimated value of IA, including a brand, is influenced by problems existring in crisis conditions, such as cost-effectiveness evaluation for brand promotion (in particular, advertising campain), company valuation, franchise valuation, etc.

\section{EASE OF USE}

Therefore, it is suggested to consider key approaches to the developed information model of company brand assessment within the marketing strategy based on mathematical model of IP assessment focusing on the present value of cash flows associated with the company brand.

In general, the concept of a brand used in marketing considerably differs from its legal interpretation. As previously noted, from the legal perspective (at least, in the Russian Federation) a brand is a trademark or a tradelabel. At present, the methods of assessment of similar IA are already well studied. In order to formalize connections between objects of the study, it is suggested to perceive the notion of a brand as a fairly stable information image remaining in consciousness of a consumer and stimulating the latter one to buy products of a certain company.

Such approach justifies the competition of brands available in the market and potentially influences the behavior of a consumer. The latter means that all image-related measures ultimately influence the probability of buying the corresponding product by the consumer only, whereas it depends on the intensity of such efforts. Thus, the flow of product purchases within each company, having a brand, represents a random process. Hence for every fixed timepoint, there is only a certain probability that among $N$ potential consumers of a specific product, the $\boldsymbol{X}$ consumers are likely to buy a product of the analyzed company (hereinafter referred to as $\mathbf{A}$ ), and $\boldsymbol{Y}=\boldsymbol{N}-\boldsymbol{X}$ products of competing brands (for simplicity, it is assumed that there is only one competing company, which further shall be referred to as $\mathbf{C})$. This probability shall be defined as $p(X, Y, t)$. It is supposed that the assessment is made within the timeframe of $t=0$, and sales are anticipated for timepoints of $t \geq 0$. The anticipated cash inflows to companies $\mathrm{A}$ and $\mathrm{C}$ are presented as follows:

$$
\begin{aligned}
& F_{A}(t)=X \cdot P_{A}(t), \\
& F_{C}(t)=Y \cdot P_{C}(t) .
\end{aligned}
$$

For simplicity, formula (1) supposes that the companies make the same product. $\mathrm{X}$ and $\mathrm{Y}$ are random values distributed within the time range of $t$ with probability $p(X, Y, t)$. In this case, cash flows $F_{A}(t)$ and $F_{C}(t)$ are random processes and used to assess their present value. Thus, when 
forming a separate brand component, it is necessary to use approaches of strategic management ${ }^{4}$.

Let us consider the change in the number of consumers of products made by companies $\mathrm{A}$ and $\mathrm{C}$ as a Markov [16] random process associated with transitions between consumer distribution in the market within timepoints of $t_{1}, t_{2}, \ldots, t_{n}$ :

$$
\{X ; Y\}_{t=t_{1}} \Rightarrow\{X ; Y\}_{t=t_{2}} \Rightarrow \cdots \Rightarrow\{X ; Y\}_{t=t_{n}}
$$

The random process (2) is described by joint probability distribution $P\left\{X_{n} Y_{n} t_{n} \mid X_{1} Y_{1} t_{1} ; X_{2} Y_{2} t_{2} ; \cdots X_{n-1} Y_{n-1} t_{n-1}\right\}$, whereas the Markov process results in: $P\left\{X_{n} Y_{n} t_{n} \mid X_{1} Y_{1} t_{1} ; X_{2} Y_{2} t_{2} ; \cdots X_{n-1} Y_{n-1} t_{n-1}\right\}=P\left\{X_{n} Y_{n} t_{n} \mid X_{n-1} Y_{n-1} t_{n-1}\right\}$

In other words, the probability of changing the number of consumers upon transition from one timepoint $\left(t_{n-1}\right)$ to another $\left(t_{n}\right)$ does not depend on probability of their distribution in the previous timepoints of $t_{1}, t_{2}, \ldots, t_{n-2}$ and is defined as shown below only by the tendency of consumers in timepoint of $t_{n-1}$ to a product of one company, defining probability of purchase of a product of this company within the time interval of $\left[t_{n-1,}, t_{n}\right]$.

Thus, the change of the number of product consumers of companies $\mathrm{A}$ and $\mathrm{C}$ represents the process falling under the category of so-called birth and death processes [16], where "birth" corresponds to a new buyer of company products and "death" - to the loss of already existing one. The probability of birth and death is defined as random causes (for example, disappearance of demand for company products of a specific consumer), and a policy of promoting the corresponding brand. As it was noted above ${ }^{5}$, the probabilistic approach, which does not describe the expected number of consumers within timeframe of $t \geq 0$, but rather the probability of a certain number of consumers of companies $\mathrm{A}$ and $\mathrm{C}$, allows describing the corresponding risks. In particular, with regard to the considered model, the risks of each company are bound to possibility of random variations of the number of expected consumers and can be described in terms of probability $p(X, Y, t)$.

The assessment of company progress on brand promotion, which is treated as the information image, motivating the consumer to buy a product of company A, deserves particular attention. Hence, the more efficient the brand is, the less uncertain the situation is with the distribution of consumers through brands existing in the market, which in general is characterized by the distribution width $p(X, Y, t)$. It should be emphasized that proactive efforts of a company aimed at brand creation and promotion will not necessarily be accompanied by its dominating role in the market. Indeed, the expected consumers are distributed between companies present in the market under the influence of several factors, whereas some of them (for instance, antitrust regulation, coordinated decision of oligopolies, etc.) are not related to a brand. At the same time, the more successful the brand is, the less uncertain the results of consumer distribution analysis will be. For example,

\footnotetext{
${ }^{4}$ See more details in [7], Chapter 3

${ }^{5}$ See more details in $[7,9]$.
}

Figure 1 shows two options of consumer distribution of company $\mathrm{A}$, which is described by the function $p(X, Y, t)$.

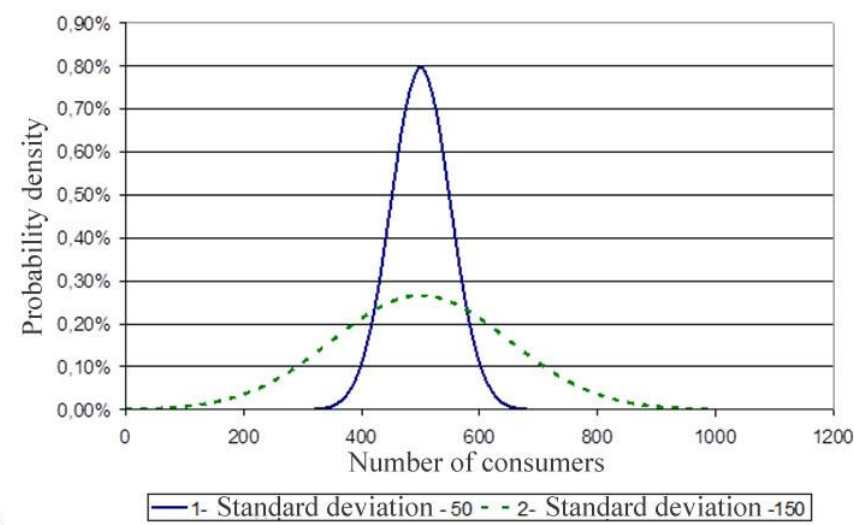

Fig. 1. Distribution of consumers with different levels of uncertainty

For every option, the average value equals $\mathrm{X}=500$ (provided that $\mathrm{N}=1000$ ) whereas the standard deviations are different. It is obvious that the second case corresponds to bigger uncertainty in consumer behavior. The information theory includes a special value for its measurement - entropy $-\mathrm{N}$, or relevant information obtained through exact definition of the consumer ratio of company $\mathrm{A}$ in the market: $H(t)=\int_{0}^{N} p(X, N-X, t) \cdot \ln [p(X, N-X, t)] d X$

It is clear that the higher the uncertainty of consumer distribution in the market between the companies, the lower the $\mathrm{X}_{\mathrm{VAR}}$ boundary determining the size of potential losses arising due to a lower number of buyers than it was expected. In this case, $\mathrm{X}_{\mathrm{VAR}}$ defines the limit below which the number of buyers will never fall with $95 \%$ probability. The relation between of $\mathrm{X}_{\mathrm{VAR}}$ and $\mathrm{N}$ is illustrated by Figure 2.

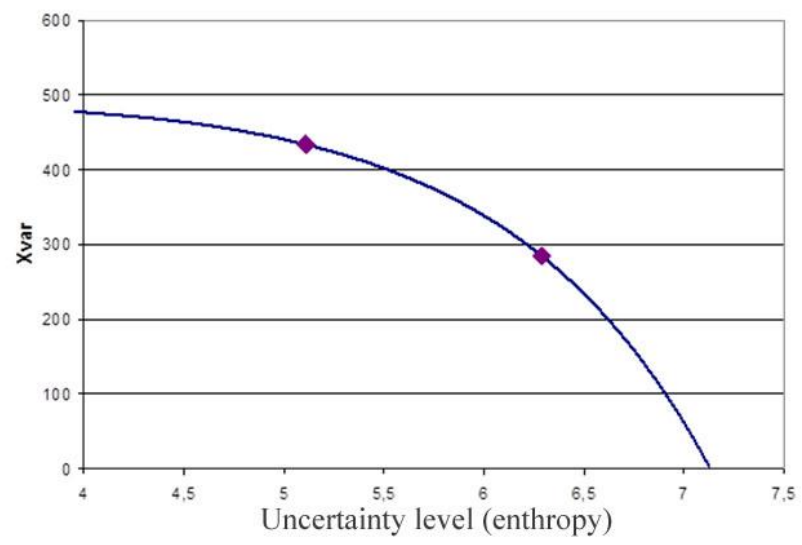

Fig. 2. Dependence of $X_{V A R}$ in (12) on the uncertainty (entropy) level of consumer distribution between companies in the market. Markers 1 and 2 correspond to distributions 1 and 2 in Fig. 2, respectively.

Thus, proceeding from the aforesaid, the following conceptual principles of the brand value model can be made on the basis of the information probability theory as a mathematical framework: 
- the use of probabilistic interpretation of consumer behavior according to which the decision on purchase of a product of either company is made with certain probability depending on the efficiency of a company brand promotion;

- the existence of an objective need for a product (for example, due to an insufficient amount of products acquired earlier or due to a new consumer) is also a random process;

- the distribution of consumers of various companies in the market formed as a result of tendencies described above is random and can be described (for two companies) through the distribution of probability $p(X, Y, t)$, where $X$ is the number of consumers of company $\mathrm{A}$, and $Y$ is the cumulative number of consumers of all competitor companies (conditionally united into one company $\mathrm{C}$ ); whereas $X+Y=N$, where $N$ is the total number of consumers in the market;

- as a measure of company success with regard to its brand promotion, the assessment of uncertainty of its consumers' distribution in the market reflecting uncertainty of their decisions on the choice of any product can be used. The entropy of distribution $H(t)$ (5) is equal to the amount of information received during precise definition of the number of consumers who made their product choice in favor of company $\mathrm{A}^{6}[13]$.

- the discount model [7, 9] of random cash flows (1), arising due to random purchase of products by consumers, is used to assess the brand value.

Such basic assumptions make it possible to formulate and solve probability equations $p(X, Y, t)$ for various specific cases [7, 9].

To illustrate the previously mentioned approach, let us consider a particular case of $p(X, Y, t)$, thus making the following assumptions:

- new consumers do not appear in the market;

- in compliance with the previous assumption, the total number of consumers of companies $\mathrm{A}$ and $\mathrm{C}$ cannot exceed $N$, i.e. $P(X, Y, T) \equiv 0$ when $X+Y>N, N=$ const.

- there are no free consumers (randomly motivated to make a purchase of products not related to a brand) in the market;

- all brand consumers belong to the group of consumers with a tough brand (i.e. under the influence of the competitors, stimulating advertisement of their number ecreases by not more than $\mathrm{e}=2.72$ times [12]);

there is no brand advertising.

Despite a big list of assumptions, the given model corresponds to a number of real markets. For example, it shall perfectly describe the behavior of consumers in metallurgy market with relatively high barriers that the companies face and generally, the probability of appearance of new consumers in a short-term perspective is small. Besides, a consumer is

\footnotetext{
${ }^{6}$ Use of this characteristics does not exclude other simpler assessments, such
} as coefficient of variation. unlikely to make a random choice of the metal products manufacturer. This choice is usually influenced by such factors as the quality of production, corresponding to processing technologies applied by the consumer; convenience of delivery; the level of logistics, etc. These factors usually lead to a steady circle of consumers of each metallurgical company, present in the market, and hence the advertising of competitors may cause outflow of some consumers, but will not result in their complete disappearance. To some degree, they reduce the efficiency of brand advertising, which allows assuming that the brand advertising is simply absent.

Calculations and mathematical modeling in economics [7, 9] make it possible to conclude that regardless the initial distribution of consumers in the market between companies A and $\mathrm{C}$, their final distribution (market share of company A) at $\lambda \cdot t \rightarrow \infty$ is defined only by relation of probabilities of repeated purchases $P_{S c d}^{C}(A)$ (repeated purchase of a product made by company A by a consumer who bought earlier a product of company $\mathrm{C}$ ) and $P_{S c d}^{A}(C)$ (repeated purchase of a product by a client of company A). The probabilities characterizing the intensity of transition of consumers from one company to another depend on relative intensity of stimulating advertising of $\mathrm{A}$ and $\mathrm{C}$. The intensity of stimulating advertising may be assessed by a number of advertising campaigns, broadcast time and, at last, advertising costs, defined as $S_{s}^{A}$ where $S_{s}^{T}$ is the general intensity of stimulating advertising of all companies present in the market. The established market share of company A is shown in Figure 3.

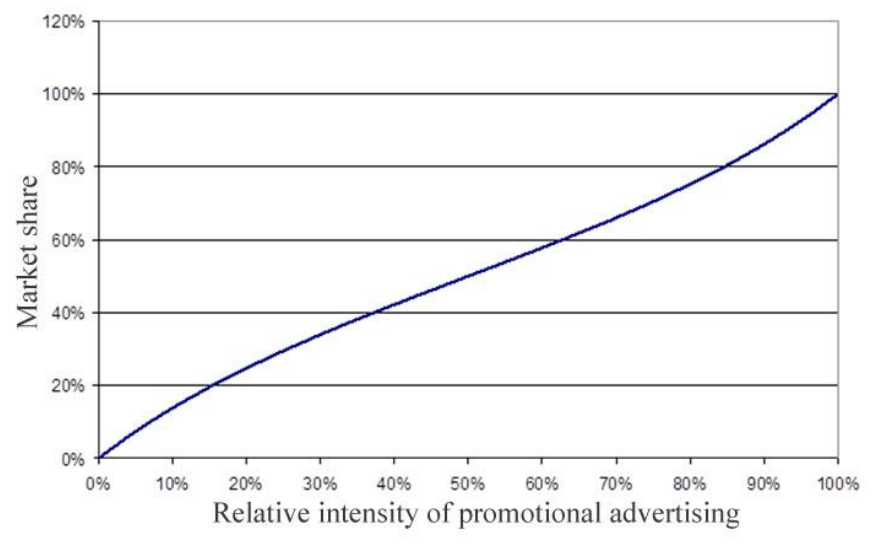

Fig. 3. Dependence of a steady market share ( $\left.\frac{M_{1}}{N}\right)$ occupied by company A on relative intensity of its promotional advertising $\left(\frac{S_{s}^{A}}{S_{s}^{T}}\right)$

The obtained ratio also allows estimating the brand cost created by company advertising. Let us consider the situation where the market share occupied by company A was established, i.e. it has stable and time independent flow of consumers occupying a certain market share:

$$
\frac{M_{1}(t \rightarrow \infty)}{N}=\frac{P_{S c d}^{C}(A)}{P_{S c d}^{C}(A)+P_{S c d}^{A}(C)}
$$


To assess the brand cost, this state is considered as a reference, and the following two scenarios can be compared:

1. Company A maintains a relative intensity of stimulating advertising $\left(S_{s}^{A} / S_{s}^{T}\right)$, which gives it the market share defined in (6). If every consumer ${ }^{7}$ per time unit generates revenue $\mathrm{R}$, then considering that the cash flow related to the presence of such consumers will be unlimited, and hence its cost may be estimated through standard discounting as:

$$
E V\left(S_{s}^{A} / S_{s}^{T}\right)=N \cdot R \cdot \frac{P_{S c d}^{C}(A)}{P_{S c d}^{C}(A)+P_{S c d}^{A}(C)} \cdot \frac{1}{W A C C}
$$

where WACC is a weighted average cost of the company ${ }^{8}$

2. The company stops its stimulating advertising $\left({ }^{A}{ }_{s}^{A} / S_{s}^{T}\right.$ $=0$, whereas $S_{s}^{C} / S_{s}^{T}=1$ ). In this case, its market share is reduced.

$$
\frac{M(t)}{N}=\frac{P_{S c d}^{C}(A)}{P_{S c d}^{C}(A)+P_{S c d}^{A}(C)} \cdot e^{-\lambda \cdot p_{0} \cdot t}
$$

where

$$
p_{0}=\left.P_{S c d}^{A}(C)\right|_{\frac{S_{s}^{C}}{S_{s}^{T}}=1}
$$

In this case, discounting the cash flow leads to:

$$
E V\left(\left[S_{s}^{A} / S_{s}^{T}\right]=0\right)=N \cdot R \cdot \frac{P_{S c d}^{C}(A)}{P_{S c d}^{C}(A)+P_{S c d}^{A}(C)} \cdot \frac{1}{W A C C+\lambda \cdot p_{0}}
$$

It is obvious that the difference in costs of discount cash flows in the first and second scenarios will give additional cost created by stimulating advertising of company A, equivalent to the cost of its brand.

$E V($ Brand $)=E V\left(S_{s}^{A} / S_{s}^{T}\right)-E V\left(\left[S_{s}^{A} / S_{s}^{T}\right]=0\right)=N \cdot R \cdot \frac{P_{S c d}^{C}(A)}{P_{c c d}^{C}(A)+P_{S c d}^{A}(C)} \cdot \frac{1}{1+\left(W A C C / \lambda \cdot p_{0}\right)}$

It is clear that the brand cost is determined by probability when competitor consumers make repeated purchases of a product made by company A under the influence of its advertising. In particular, in case when the probability of repeated purchase of a product by consumers significantly exceeds the probability of the reverse process (consumers do not buy a product of company A) (10) is especially evident):

\footnotetext{
${ }^{7}$ It should be noted that all consumers are roughly the same, i.e. the revenues they bring are also approximately the same. If this assumption is unfair, there is a need to either hold additional consumer segmentation (for example, large, average, small) or to consider an additional random process that takes into account the probability of purchase of fixed revenues of companies A and C $p\left(R_{A}, R_{C}, t\right)$. Any model described above can be used for various specific tasks. See more details in the following papers.

${ }^{8}$ See more details on WACC in [8].
}

$$
E V(\text { Brand }) \approx N \cdot R \cdot\left\{1-\frac{P_{S c d}^{A}(C)}{P_{S c d}^{C}(A)}\right\} \cdot \frac{1}{1+\left(W A C C / \lambda \cdot p_{0}\right)}
$$

Such ratios may be applied for the assessment of advertising campaign's efficiency. It is necessary to compare the brand cost (11) achieved as a result of brand cost advertising campaign with discount cash flow associated with maintaining the existing advertising efficiency $E V_{A}$. The following situation corresponds to efficient advertising:

$$
E V(\text { Brand })>E V_{A}
$$

For example, for the company, selling its products daily, with the demand $(\lambda=1 / 365)$, using the aforementioned ratios (7-11), it is easy to find that the brand cost makes $18 \%$ of its total $\operatorname{cost}^{9}$. Let us now consider the second scenario of $\mathrm{M}_{2}(\mathrm{X})$ with random variable $X$ as it was stated above [7, 9], the degree of uncertainty of consumer distribution in the market together with corresponding risks is:

$$
M_{2}(X)=\sum_{X=1}^{N} X^{2} \cdot p(X, N-X, t)
$$

The equation for $\mathrm{M}_{2}(\mathrm{X})$ is not given due to its awkwardness. Knowledge of $\mathrm{M}_{2}(\mathrm{X})$ allows defining a standard deviation (dispersion) of consumer distribution in company A. By defining $\mathrm{M}_{2}(\mathrm{X})$ for relatively large times $\lambda \cdot t \rightarrow \infty$, corresponding to the established distribution of consumers in the market, the following is found:

$$
\sigma=\sqrt{M_{2}-M_{1}^{2}}=\sqrt{N} \cdot \frac{\sqrt{P_{S c d}^{C}(A) \cdot P_{S c d}^{C}(A)}}{P_{S c d}^{C}(A)+P_{S c d}^{A}(C)}
$$

Figure 4 shows the dependence of variation coefficient $C_{v}=\sigma / M_{1}$ on efficiency of stimulating advertising. The less the variation coefficient is, the less uncertain the company market share and risks associated with it are.

The given example illustrates the efficiency of the suggested method.

The probabilistic approach offered within the information model of brand assessment can be used both for the estimation of a brand cost and for the development of a suitable advertising strategy in far more difficult conditions. The introduction of the suggested method requires further sociological surveys that allow defining parameters to be included into the aforementioned relations.

For instance, in case of availability/lack of brand advertising in the markets of metallurgy and construction, the conducted study of consumer distribution allow carrying out the corresponding calculations and receiving diagrams. Thus, consumer distribution in the presence of brand advertising is presented in Figure 5. Figure 5 clearly demonstrates the plateau in the area corresponding to average intensity of brand advertising. This reflects an increase in the share of consumers

\footnotetext{
${ }^{9}$ For the assessment, the WACC $=25 \%$.
} 
with ideal and rigid relation to a brand. The distribution of consumers without brand advertising is shown in Figure 6.

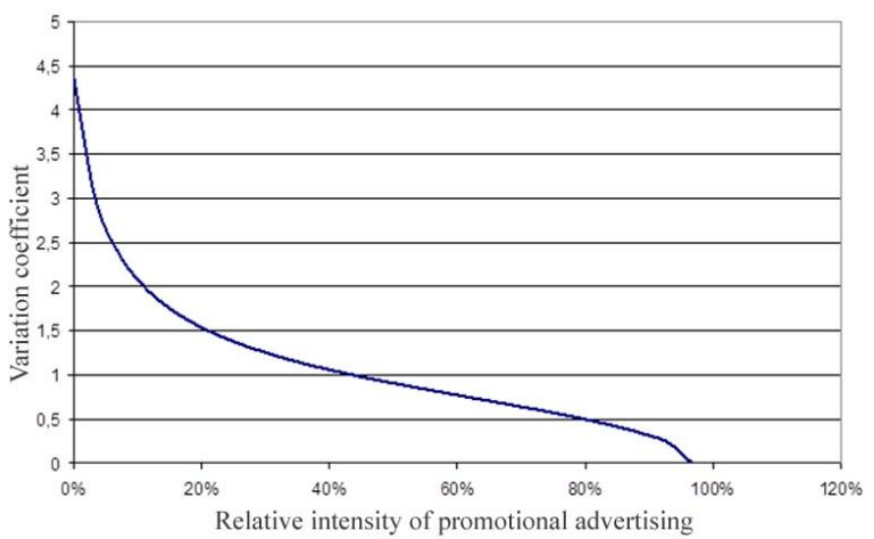

Fig. 4. Dependence of established variation coefficient of the market share ( $\sqrt{N} \cdot C_{V}$ ) occupied by company A on the relative intensity of its promotional $\operatorname{advertising}\left(\frac{S_{s}^{A}}{S_{s}^{T}}\right)$

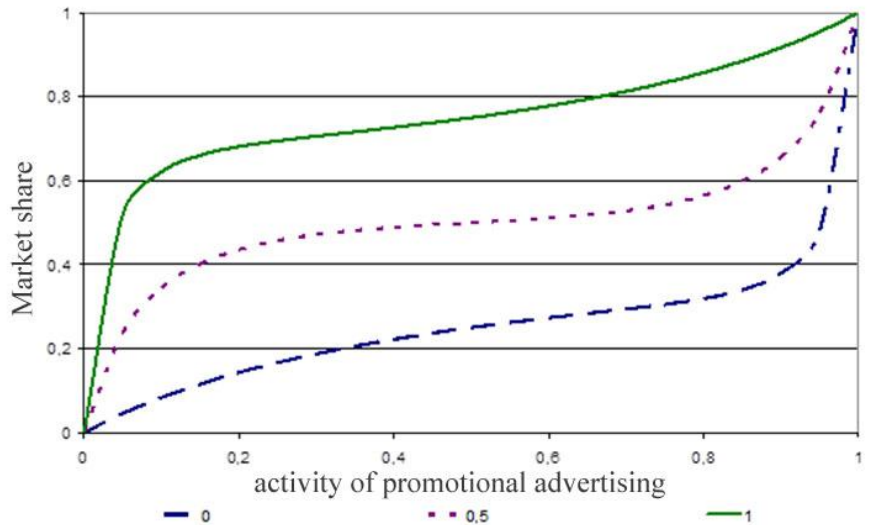

Fig. 5. Dependence of the market share on promotional advertising of company A with various efficiency of brand advertising $\left(S_{B}=0 ; 0.5 ; 1\right)$

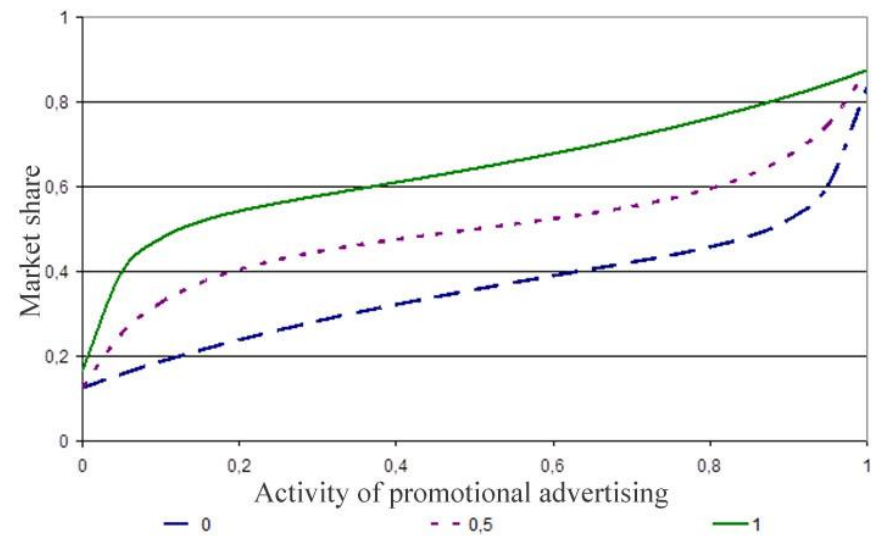

Fig. 6. Dependence of the market share on efficiency of stimulating advertising of company A with different efficiency rate of brand advertising $\left(S_{B}=0 ; 0.5 ; 1\right)$ in the binary market $P_{L}=0.5, P_{B}=0.5$
As Figures 5 and 6 show, the method considered will even be applicable in case when the company stops all other types of advertising activity.

\section{References}

[1] N.V. Bulgakova, Do enterprises need intellectual property? Personal journal, September 29, 2007

[2] I.B. Ardashkin, Phenomenology of scientific problems: from classical to post-classical science: thesis synopsis of Dr. of Philology: 09.00.01 Tomsk, 2011, pp. 41.

[3] G.A. Barysheva, Intellectual resources and launch of scientific products in the market: thesis of Dr. of Economics: 08.00.01, Tomsk, 2002, pp. 386.

[4] A.V. Bulanov, Brand 2.0. From philosophy to practice, Moscow: JSC Krasnaya Zvezda, 2013, pp. 496.

[5] V.S. Vladimirov, Generalized functions in mathematical physics, Moscow, 1979.

[6] V. Esipov, G. Malakhov, B. Terekhov, Business valuation, St. Petersburg, 2001

[7] G.V. Astratova, E.V. Sinitsyn, Intellectual services in information society. Scientific monograph, Ekaterinburg, Printed with original layout at AMB Publishing House, 2009, pp. 250.

[8] V.V. Kovalev, Introduction to financial management, Moscow, 1999.

[9] G.V.Astratova, L.I. Ponomareva, Professional education in Russia as a tool for transition to information society. Scientific monograph, Yekaterinburg Shadrinsk, 2009, pp. 368

[10] Development of the intellectual services market in conditions of the global financial crisis. Scientific monograph, Yekaterinburg: QVANT-2, 2009, pp. 392

[11] M.V. Ryzhkova, Socio-economic factors of consumer behavior: research methodology, Thesis synopsis of Candidate of Economics: 08.00.01: Tomsk, 2003, $12 \mathrm{p}$.

[12] Yu. Ryazanov, G. Shmatov, Media Planning, Ekaterinburg, 2002

[13] V.S. Korolyuk, Handbook on probability theory and mathematical statistics, 1978

[14] S.A. Sudarikov, Intellectual property rights, M .: Prospekt, 2009, pp. 368.

[15] A.I. Tatarkin, E.V. Pilipenko, Knowledge economy: problems of theory and methodology, Yekaterinburg: Institute of Economics, Ural Branch of RAS, 2007, pp. 284.

[16] Feller V., Introduction to probability theory and its applications. M .: 1964.

[17] Global Marketing Strategies, Jean-Pierre Jeannet, H. David Hennessey, 3-d ed. Boston-New Jersey: Houghton Mifflin Company, pp. 896

[18] Kotler Philip, Armstrong Gary, Principles of Marketing, 6-th ed. - New Jersey: Paramount Communications Company, 1994, pp. 692.

[19] Kotler Philip, Fernando Thas de Bes, Winning at innovation: The A-to-F Model. Palgrave Macmillan, 2011, pp. 272.

[20] Leon G. Schiffman, Leslie Lazar Kanuck, Consumer behavior, 4-th ed. New Jersey: Prentice Hall, Inc., 1991, pp. 800

[21] J.Y. Wind, Product Policy: Concepts, Methods and Strategy, Reading: Mass., Adisson Wesley, 1982

[22] J.Y. Wind, V. Mahajan, D.S. Swire, An empirical comparison of standadized portfolio models, J. of Marketing, V. 47, pp. 89-99, 1983 